\title{
Particularidades do Imperfetto no LiVRo DIDÁTICO DE ITALIANO L2 NUOVO ESPRESSO 2
}

\author{
Leandro Vidal Carneiro* \\ Fernanda Suely Muller * *
}

\begin{abstract}
RESUMO: Tendo em vista a premissa dos propósitos comunicativos desde as correntes funcionalistas (PEZZATI, 2011), bem como sua apresentação e possível aplicação nos mais recentes materiais didáticos inseridos no contexto comunicativo do pós-método (KUMARAVADIVELU, 2006), pretendemos, neste artigo, discutir a apresentação e a abordagem dos valores tempo-aspectuais do imperfetto no material didático Nuovo Espresso 2 (BALİ; RIZZO, 2014). De modo ainda mais específico, sublinhamos o imperfetto apresentado no manual em questão pela perspectiva do modo realis e as estratégias didáticas utilizadas pelas autoras durante as fases de globalidade, análise, reflexão e síntese. Os resultados apontam que as autoras primam as funções iterativa e descritiva do passado imperfectivo do italiano, apresentando textos motivadores e prototípicos da ocorrência dessas funções, a fim de que o aprendiz alcance as seguintes competências comunicativas: narrar fatos da infância, contar sobre viagens e hábitos do passado ou descrever situações passadas; e encerra com exercícios de verificação da aprendizagem que contemplam a capacidade do aprendiz de relacionar, completar tabelas e textos com formas verbais ou com outros elementos do texto, completar e/ou ligar frases, escolher a expressão adequada e identificar funções. Embora haja um equilíbrio na apresentação dessas duas funções, os dados colhidos atestam que as autoras não apresentam no material didático a função narrativa do imperfetto, desconsiderando-a totalmente.
\end{abstract}

* Centro de Línguas do Instituto Municipal de Desenvolvimento e Recursos Humanos, Fortaleza (Brasil) - leandrovidallp@gmail.com

** Universidade Federal do Ceará, Fortaleza (Brasil) - fernanda.muller@letras.ufc.br

DOI: http://dx.doi.org/10.11606/issn.2238-8281.v0i35p54-83 
PALAVRAS-CHAVE: ensino de italiano L2; tempos verbais; gramática; análise de material didático em língua italiana.

ABSTRACT: Muovendo dall'approccio funzionalista (PEZZATI, 2011) e giungendo ai più recenti materiali didattici inseriti nel contesto comunicativo del post-metodo (KUMARAVADIVELU, 2006), il presente articolo si prefigge di discutere sia l'approccio sia il modo in cui vengono proposti i valori tempoaspettuali dell'imperfetto nel materiale didattico Nuovo Espresso 2 (BALİ; RIZZO, 2014). In maniera ancora più specifica, viene analizzato l'imperfetto presentato nel manuale in oggetto secondo la prospettiva del modo realis e le strategie didattiche utilizzate dalle autrici durante le fasi di globalità, analisi, riflessione e sintesi. I risultati indicano che le autrici privilegiano la funzione iterativa e descrittiva del passato imperfettivo dell'italiano, presentando testi motivatori e prototipici quanto al ricorrere di queste funzioni, affinché il discente raggiunga le seguenti competenze comunicative: narrare fatti dell'infanzia, raccontare viaggi e abitudini del passato o descrivere situazioni passate, il tutto concludendosi con esercizi di verifica dell'apprendimento che contemplano la capacità del discente di completare tabelle e testi con forme verbali o con altri elementi testuali, completando elo collegando frasi, scegliendo l'espressione adeguata e identificando funzioni. Nonostante esista un equilibrio nella presentazione di queste due funzioni, i dati raccolti attestano che le autrici non presentano nel materiale didattico la funzione narrativa dell'imperfetto, ignorandola completamente.

PAROLE CHIAVE: insegnare italiano L2; tempi verbali; grammatica italiana; analisi del materiale didattico in italiano

ABSTRACT: In this paper, we discuss the presentation and approach of verb tenses and aspectual values of the imperfect tense in Nuovo Espresso 2 (BALİ; RIZZO, 2014) textbook, according to the most recent ideas about second language teaching in the communicative context of the post-method (KUMARAVADIVELU, 2006) and the premise of the communicative purposes from the functionalist currents (PEZZATI, 2011) as well. In an even more specific way, we address the imperfetto presented in this textbook from the perspective of the real mode and the didactic strategies used by the authors during the phases of globality, 
analysis, reflection and synthesis. The results point out that the authors emphasize the iterative and descriptive functions of the imperfect tense of Italian, presenting motivational and prototypical texts of the occurrence of these functions, so that the learner can achieve the following communicative competences: narrating facts from childhood, telling about trips and habits of the past or describe past situations, ending up with learning verification exercises that include the apprentice's ability to relate, complete table, texts, with verbal forms, or other elements of the text, complete and/or link phrases, choose appropriate expressions, and identify functions. Although there is a balance in the presentation of these two functions, the data collected attest that the authors do not present in that textbook the narrative function of the imperfect, totally disregarding it.

KEYWORDS: teaching Italian L2; verb tenses; grammar; analysis of Italian textbook. 


\section{Introdução}

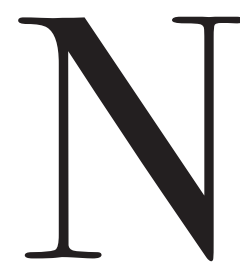

este trabalho, apresentamos os resultados de uma pesquisa que buscou trazer à luz as particularidades do imperfetto na abordagem escolhida pelo manual Nuovo Espresso 2 (BALİ; RIZZO, 2014).

O trabalho foi assim estruturado: na primeira seção, "Considerações sobre a classe verbal", apresentamos considerações sobre a classe verbal e duas de suas categorias, o Tempo e o Aspecto (BERTINETTO, 1986; COROA 2005; COSTA, 1997; TOTH, 1999a, 1999b), relacionando-as às reflexões sobre o passado imperfectivo da língua italiana sistematizadas por Farkas (1998) e Serianni (1988). Na segunda seção, “Análise do imperfetto no material didático Nuovo Espresso 2", acrescentamos considerações sobre os procedimentos didáticos de apresentação do imperfetto no referido material, baseados, sobretudo, em Balboni (2002, 2010), a fim de verificar a abordagem dada às funções do imperfetto estabelecidas pelos linguistas em apreço e compreender a progressão dos argumentos ao longo das unidades. Na terceira seção, "Análise do imperfetto", apresentamos os dados referentes à coleta e à análise 
do par forma/função no referido material. Em seguida, apresentamos nossas considerações finais acompanhadas das referências bibliográficas.

\subsection{Considerações sobre a classe verbal}

A partir da difusão das correntes funcionalistas, a linguagem passou a ser analisada considerando-se os propósitos comunicativos dos seus usuários. Nessa perspectiva, passouse a considerar como os elementos linguísticos são usados pelos usuários da língua para transmitir suas mensagens e produzir sentidos (PEZZATI, 2011). Nesse percurso, os verbos, tomados como elementos fundamentais na formação dos sentidos dos enunciados, passaram a ser analisados de acordo com a função que desempenham na constituição do discurso.

Essa nova maneira de analisar o fenômeno verbal "contrasta com a maneira tradicional de considerar o verbo apenas a palavra que exprime ação, estado ou fenômeno e que apresenta grande variedade de formas para expressar também o modo, o tempo, a pessoa, o número e a voz" (VARGAS, 2011, p.10). Conforme Vargas,

Por serem importantes elementos na produção do sentido dos textos, as formas verbais não podem ser analisadas apenas em sua constituição morfológica ou por meio de sua função sintática. Importa verificar em que medida contribuem para essa construção do sentido dos textos e o quanto refletem a intenção do sujeito que as seleciona para comunicar-se (2011, p.18).

A autora não quer, com isso, dizer que um estudo das formas não seja útil. Pelo contrário, considera necessário ter consciência das formas que a língua oferece para que se possam estabelecer relações. Não se trata, obviamente, das relações que as gramáticas normativas cunham, as quais tratam exaustivamente a análise morfossintática, atribuindo-lhe complexas nomenclaturas, que pouco ou nada acrescentam à compreensão dos sentidos dos enunciados. Trata-se muito mais de um modo de compreender como e por que as formas linguísticas são aplicadas em enunciados, quais são as motivações que determinam tais escolhas e quais são, na comunicação, os resultados dessas escolhas. Em suma, como tais formas constroem sentidos.

Consultando a explanação sobre a classe verbal em uma renomada gramática da língua italiana, encontramos a seguinte definição: "O verbo é a parte variável do discurso que, isoladamente ou em conjunto com outros elementos, fornece informações sobre o sujeito da frase inserindo-as no tempo" (SENSINI, 1990, p.217). Em nota de rodapé, o autor acrescenta: "O termo 'verbo' vem do latim verbum, 'palavra'. O verbo, de fato, é a palavra por excelência: a palavra mais importante, sem a qual não é possível formular um pensamento de significado completo". 
É curioso que essa característica - a palavra mais importante do discurso, porque sem ela não se formula um pensamento de sentido completo - seja relegada ao pé da página, apresentando-se, pois, como uma informação periférica, e não central, como o próprio enunciado deixa claro. Ainda sobre a classe verbal, o gramático acrescenta que uma das funções do verbo é "aquela de inserir no tempo a informação que o mesmo fornece em relação ao sujeito" (SENSINI, 1990, p.217).

Destaca, desse modo, uma particularidade muito importante dessa classe plurifuncional: relacionar ao tempo cronológico, ao tempo do mundo, o quanto dito no enunciado.

\subsection{Considerações sobre Tempo e Aspecto}

A expressão linguística do Tempo é a manifestação de uma característica cognitiva universal: o tempo cronológico. Segundo Comrie (apud CORÔA, 2005), o tempo gramatical é a gramaticalização da localização do tempo cronológico. Reichenbach (1947 apud CORÔA, 2005), propondo sua teoria para a estruturação dos tempos verbais, parte do pressuposto de que estes determinam o tempo em relação a um ponto de referência e ao momento do ato de fala de um dado enunciado. Como a enunciação é egocêntrica, o falante relaciona tudo ao seu ponto de vista, distribuindo e organizando "no tempo e no espaço os fatos e os objetos de que fala, tomando como ponto de partida o momento e o local em que se encontra" (COSTA, 1997, p.16).

Considerando esses aspectos, Reichenbach (1947), propõe uma descrição de como os tempos linguísticos se relacionam com o fenômeno do tempo cronológico, formulando uma linha temporal sobre a qual instaura três pontos fundamentais: o momento da enunciação/fala (MF), o momento do evento (ME) e o momento de referência (MR). O primeiro, MF, é um momento do tempo cronológico em que um falante produz um enunciado; o segundo, ME, é o momento ao qual se refere o enunciado produzido pelo falante (MF), é o momento em que o evento (estado, processo, ação) acontece; o terceiro, MR, é um fragmento de um tempo cronológico já devidamente atualizado no discurso e que o falante toma como ponto de partida para localizar o momento ao qual a sua enunciação se refere, podendo ser, inclusive, outro evento localizado temporalmente já em relação ao MF.

Estabelecido o MF como momento central da enunciação, Reichenbach (1947) formula que há apenas três momentos que podem servir de MR para os eventos descritos pelo discurso e que dois desses momentos se relacionam diretamente com o MF, são eles: presente, passado e futuro, aos quais chama "tempos absolutos", estabelecendo três divisões fundamentais para a localização dos eventos verbais na linha do tempo: presente, passado e futuro, que correspondem, respectivamente, à concomitância com o MF, à anterioridade ao $\mathrm{MF}$ e à posterioridade ao MF. Têm-se, então, a seguinte configuração: 
Presente - MF, ME, MR concomitantes;

Passado - MF e MR concomitantes e ME anterior a esses;

Futuro - MF e MR concomitantes e ME posterior a esses.

A esses tempos, Reichenbach (1947) acrescenta os tempos relativos, que são aqueles que tomam como ponto de referência um tempo absoluto. Segundo o linguista, as línguas do mundo podem apresentar as seguintes configurações para expressar:

a. Um passado de um passado: ME anterior a MR, que é, por sua vez, anterior a MF;

b. Um presente de um passado: ME e MR concomitantes e anteriores ao MF;

c. Um futuro de um passado: ME posterior a MR, que é anterior a MF;

d. Um passado de um futuro: ME anterior a MR, que é posterior a MF;

e. Um presente de um futuro: ME e MR concomitantes e posteriores a MF;

f. Um futuro de um futuro: ME posterior a um MR, também posterior a MF.

Essas configurações são as mais recorrentes nas línguas que existem no mundo. Contudo, nem todas as línguas fazem uso de todas essas configurações ou não possuem formalização para todas, usando, quando necessário, perífrases para expressar algumas delas. Isto porque, como afirma Jakobson (1969), “a verdadeira diferença entre as línguas não reside no que se possa ou não exprimir, mas no que deve ou não ser expresso pelos que as falam".

Sob esse prisma, a categoria Tempo é, pois, uma categoria dêitica, que depende da localização do falante no ato da enunciação para que ela possa ser atualizada. Tem como referência, portanto, o tempo cronológico, referindo-se às noções de presente, de passado e de futuro. Isto é, a categoria estabelece em que momento do tempo físico do mundo o enunciado é produzido, é a espacialização do enunciado em um momento do tempo físico. Desse modo, a categoria Tempo é característica tanto da sentença quanto da enunciação, a qual se apoia no tempo físico do mundo.

A categoria Aspecto, por sua vez, tem como referência o tempo interno de cada evento verbal, o ME, isto é, o tempo físico que os compõe. Faz referência ao momento do desenrolar do processo verbal, e não tem relação alguma com o momento da enunciação, o MF (CORÔA, 2005), isto é,

O Aspecto é indiferente a qualquer problema de localização ou de ordenação recíproca de eventos permitindo até, pelo contrário, de destacar certas valências semânticas específicas que são inerentes aos tempos verbais em relação à visualização diferente do processo adotado 
de tempos em tempos pelo locutor (BERTINETTO, 1986, p.77-78) (tradução nossa). ${ }^{1}$

A categoria Aspecto trata da constituição temporal interna de uma situação (COMRIE, 1976 apud CORÔA, 2005), das diferentes maneiras de ver essa constituição, através da qual se marca a duração da situação e/ou suas fases.

Tóth (1999b, p.04) assim a define:

O Aspecto é uma categoria que transmite as diversas modalidades de desenvolvimento da ação no tempo, ou seja, a categoria através da qual o falante, dependendo das suas intenções comunicativas, "visualiza", "apresenta" a ação em si, escolhendo entre as diferentes formas existentes e destacando uma ou outra modalidade particular de desenvolvimento (tradução nossa). ${ }^{2}$

É, desse modo, uma categoria marcada pela perspectiva do falante, sendo, pois, uma característica da sentença. Não deve, contudo, ser confundida com o Modo, categoria que expressa as nuances de envolvimento/afastamento do falante sobre o quanto enunciado, bem como a realidade/irrealidade das proposições.

Segundo Šabršula (1972 apud CORÔAA, 2005, p.63), "o Aspecto apresenta uma oposição binária: perfectivo e imperfectivo; além dessa oposição não há Aspecto, o que há são alguns fenômenos intimamente ligados a ele". As noções de perfectivo e de imperfectivo remontam ao étimo latino: perfectum, concluído, e infectum, não concluído. Por meio do Aspecto perfectivo, "o falante vê o evento como limitado, sem que sua duração ou o seu desenvolvimento sejam relevantes" (CORÔA, 2005, p.64), isto é, o tempo do evento é visto como um todo, do qual não é evidenciado o início, o curso, a duração ou o fim. Desse modo, o Aspecto perfectivo "implica necessariamente que o fato verbal seja visto como um todo no qual se inclui o ponto terminal" (COSTA, 1997, p.33).

1 No original: "l'aspetto è indifferente a qualunque problema di localizzazione o di ordinamento reciproco degli eventi, e consente piuttosto di portare alla luce certe specifiche valenze semantiche che ineriscono ai tempi verbali in relazione alla diversa visualizzazione del processo adottato di volta in volta dal locutore."

2 No original: "l'aspetto è una categoria che trasmette le diverse modalità di svolgimento dell'azione nel tempo, per meglio dire, categoria attraverso la quale il parlante, a seconda delle sue intenzioni comunicative, 'visualizza', 'presenta' l'azione stessa, scegliendo tra le diverse forme e mettendo in rilievo così l'una come l'altra modalità di svolgimento." 
Com o imperfectivo, o falante considera a temporalidade interna do evento, marcando-a de algum modo, "ou considerando-a como um fragmento de tempo que se desenrola - expressão da cursividade - ou selecionando fases desse tempo interno - expressão das fases inicial, intermediária ou final" (COSTA, 1997, p.30). É como se o falante se inserisse no evento e pudesse ver e acompanhar o desenrolar do processo. Essa metáfora espacial permite que se veja o processo como uma extensão na linha do tempo, e não mais como apenas um ponto. Assim, o Aspecto "é compatível com qualquer noção temporal e não excluído por ela" (CORÔA, 2005, p.64).

Segundo Tóth (1999a) o Aspecto perfectivo é marcado com o sema da totalidadeterminatividade, no sentido de que o evento expresso perfectivamente é visto como global e não fragmentado, isto é, não se destaca nenhuma fase do desenvolvimento da situação verbal. Por outro lado, o imperfectivo é marcado com o sema da indeterminação, isto é, com esse valor aspectual, o falante destaca algum momento do desenrolar da ação, e não determina, pelo menos, um dos lados do limite - início ou término do evento.

Bertinetto (1986, p.83), em linha do que assevera Šabršula (op. cit.), afirma que "se nos baseássemos apenas nas características morfológicas da conjugação, não haveria muito a observar sobre o Aspecto em italiano, além da fundamental oposição Imperfeito e Perfeito", e acrescenta que o problema é de natureza estritamente semântica, que a presença de oposições morfológicas são um mero expediente externo para a expressão de distinções mais profundas e tendencialmente universais.

\subsection{Considerações sobre o imperfetto italiano}

Farkas (1988) destaca três áreas expressas pelo imperfetto italiano: Tempo, Modo e Aspecto. Tóth (1999a) acrescenta que, a par do que acontece nas línguas eslavas, em que o aspecto é morfologizado, isto é, recebe formalização, o imperfetto italiano apresenta uma nítida solidariedade tempo-aspectual, a ponto de os valores aspectuais, não possuindo morfologização própria, serem expressos, em nível semântico-sintático, através da categoria do Tempo.

Neste trabalho, ocupar-nos-emos dos valores tempo-aspectuais do imperfetto italiano. Deixaremos fora da análise, portanto, os valores modais que essa forma congrega. Todavia, se necessário para confrontos e explanações sobre aqueles valores, faremos algumas breves explanações sobre estes. Isto porque, segundo o quanto afirma Tóth (1999a, p.4-5), o imperfetto, quando assume valores modais, "não só não perde suas características temporais e 
aspectuais, mas tais características (...) são indispensáveis para a realização dos valores modais em questão." (tradução nossa). ${ }^{3}$

Separando os percursos do aspecto perfectivo e do aspecto imperfectivo, Salvi e Vanelli (1992, p.53) consideram "o imperfeito e o aspecto indeterminativo italiano como uma forma verbal adequada para expressar a indeterminação em relação ao desenvolvimento posterior do evento ou sobre o número de repetições do evento considerado" (tradução nossa). ${ }^{4}$ Serianni (1988) já destacara a incompletude da ação no passado expressa pelo imperfetto, acrescentando que "as coordenadas da ação passada (tempo de início, conclusão etc) permanecem não expressadas". O imperfetto é, pois, um tempo que apresenta o evento "em curso em um determinado momento de referência no passado. Serve, portanto, como um cenário para eventos perfectivamente presentes" (SALVI; VANELLI, 1992, p.56) (tradução nossa). ${ }^{5}$

Das configurações estabelecidas por Reichenbach (1947 apud CORÔA, 2005), o imperfeito é, em critérios temporais, um presente de um passado, uma vez que ME e MR são concomitantes e anteriores ao MF. De fato, de acordo com Tóth,

O presente, como tal, admite que o momento do acontecimento inclua o momento da enunciação de tal maneira que a ação esteja em curso no mesmo momento em que é a mesma é pronunciada. Isso também significa que, do ponto de vista do momento da enunciação, a ação pode ser considerada como um processo que pode ser contra distinguido com o sema de duração, incompletude, indeterminação (1999a, p.05, grifos no original, tradução nossa). ${ }^{6}$

Porque o presente é o tempo em que o ME é concomitante ao MR, e estes concomitantes ao MF, o seu correspondente temporal para fatos ocorridos no passado, é, diretamente o

3 No original: "non solo non perde le sue caratteristiche temporali e aspettuali, ma tali caratteristiche (...) sono indispensabili per il realizzarsi dei valori modali in questione."

4 No original: "l'imperfetto e l'aspetto indeterminativo italiano come forma verbale adatta a esprimere 'l'indeterminatezza circa l'uteriore svolgimento dell'evento o circa il numero di ripetizioni dell'evento considerato' ".

5 No original: "in corso in un dato momento di riferimento nel passato. Serve quindi per fare da sfondo a eventi presenti perfettivamente"

${ }^{6}$ No original: "Il presente, come tale, ammette che il momento dell'avvenimento includa il momento dell'enunciazione in modo tale che quando si parla, l'azione di cui si parla è sicuramente in corso. Questo significa anche che, dal punto di vista del momento dell'enunciazione, l'azione può essere considerata come un processo che può essere contrassegnato con il sema di duratività, incompiutezza, indeterminatività” 
imperfeito, tempo no qual o ME e MR são, também, concomitantes, mas anteriores ao MF. Desse modo, o imperfeito carrega consigo alguns dos semas aspectuais do presente, tais como a duração, a incompletude, a indeterminação.

No domínio da imperfectividade, o passado imperfectivo, segundo Freitag (2011), recobre os seguintes valores:

a. Aspecto progressivo: indica um processo colhido em um único instante do seu desenvolvimento. As condições mais importantes para definir o aspecto progressivo parecem ser a existência de um instante de focalização no qual o processo é observado em pleno curso do seu desenvolvimento, e o estado de indeterminação acerca da prossecução do processo além desse instante: In quel momento Luca nuotava energicamente;

b. Aspecto habitual: diz respeito à regularidade de ocorrências de um evento. A visão habitual considera cada microevento do macroevento como concluso (BERTINETTO, 1996); a imperfectividade consiste, pois, na implicação de indeterminação, seja em relação ao número de repetições, seja em relação à eventual prossecução da serie de microeventos: In quel periodo Luca correva ogni pomeriggio.

c. Aspecto contínuo: implica uma ideia de indeterminação em relação à prossecução ou em relação ao número de repetições do processo; mas, diferentemente do aspecto progressivo, não contempla a individualização de um único instante de focalização; e, à diferença da acepção habitual, contempla a identificação de um quadro situacional único. Il bambino piangeva.

Para o imperfetto italiano, Serianni (1988) distingue os seguintes valores tempo-aspectuais:

a. imperfetto descritivo: utilizado nas descrições, incarna perfeitamente a indeterminação do tempo: Era un ragazzo solare, aveva i capelli biondi e gli occhi azzurri;

b. imperfetto iterativo: usado para expressar a repetição das ações num determinado espaço de tempo; acentua, portanto, o caráter habitual de um evento, quase sempre acompanhado com advérbios de frequência: Mia sorella mangiava sempre la pasta con un filo d'olio;

c. imperfetto narrativo: imperfetto no lugar do passato prossimo, com o escopo de narrar uma sequência de eventos perfectivos - concluídos no passado -, mas imperfectivizados, a partir da perspectiva do falante, que se engaja nas ações narradas e as visualiza do seu ponto de vista,

Trata-se, portanto, de uma particular colocação espaço-tempo do falante em relação aos eventos, em consequência das quais a sobreposição 
das coordenadas temporais dos eventos e as coordenadas espaciais do falante faz surgir um sentimento no interlocutor (ou, melhor, no leitor) semelhante a uma constelação de efeitos espaciais e temporais, como se estivesse assistindo uma cena de filme (lembrando de que a localização espacial da ação é confiada à categoria de pessoa) (TÓTH, 1999b, p. 3-4, tradução nossa). ${ }^{7}$

Esse imperfetto parece, todavia, não dar conta da predisposição imperfectiva, aproximandose mais de características perfectivas. Serianni (1988) explica que seu ofício estilístico é prolongar a ação do evento verbal, imobilizando-a, em certo modo, diante dos olhos do leitor: Carlo Giovannesi usciva di casa alle 9.06 e si trovava davanti alla metro alle 10 in punto, dopodiché arrivava in piazza di Spagna alle 10.35 e li portava a termine la transazione;

d. imperfetto conativo; para enunciar projetos, desejos, ações que não se completaram. Es. Quasi quasi cadevo dalla sedia!

e imperfetto di modestia: usado para exprimir um desejo, como se quisesse dizer "queria fazer assim, mas, se você não quiser, não importa": Volevo venire a trovarti mercoledì. Ou pode ser utilizado quando se tem a intenção de colocar-se a disposição do interlocutor: Voleva?; possui valor modal, como nas situações típicas de uso das frases: "Volevo un caffé", sendo, desse modo, comutável com o condizionale: "vorrei un caffe".

f. imperfetto irreale; característico da língua falada, encontrado também em algumas narrativas, é usado no lugar do condizionale passato para indicar a hipotética consequência de uma ação que não se realizou no passado: Se mi chiamavi, venivo;

g. imperfetto onirico e ludico: Utilizado nas descrições dos sonhos: Ho fatto un brutto sogno. Ero a Genova e cadevo dalla montagna rotolando nel burrone; e nas brincadeiras infantis: io ero il farabutto e lui l'uomo di legge.

h. imperfetto prospettivo: utilizado, no lugar do condizionale passato, para indicar o futuro no passado: Marta era arrivata mercoledì mattina e ripartiva giovedì sera. ("sarebbe ripartita giovedì sera").

7 No original: "Si tratta dunque di una particolare collocazione spazio-temporale del parlante rispetto agli avvenimenti, in conseguenza della quale la sovrapposizione delle coordinate temporali degli eventi e delle coordinate spaziali di chi parla (ricordiamo che la collocazione spaziale dell'azione è affidata alla categoria di persona), cioè una costellazione di effetti spaziali e temporali, fa insorgere una sensazione tale nell'interlocutore (o, meglio, nel lettore) come se guardasse una scena cinematografica." 
Do exposto, retira-se que os três primeiros tipos são usados em situações de caráter real (modo realis), enquanto os outros se situam em um plano de irrealidade, pressuposição, incerteza e imaginação (modo irrealis). Com o exposto referencial teórico, verificaremos, na seção a seguir, quais - e como - dessas características do imperfetto italiano são destacadas e abordadas pelo material NE2.

\section{Análise do Imperfetto no material didático Nuovo Espresso 2}

\subsection{Descrição do material didático}

Nuovo Espresso (doravante NE) é um curso de língua e cultura italiana para estrangeiros. O volume dois é destinado a estudantes de nível pós-elementar-intermediário. O material didático do volume cobre aproximadamente 90 horas de curso, e a este número somam-se outras horas que o aluno deve dispensar para as atividades de vídeo-curso e os exercícios para casa. O conjunto do material didático de NE2 é composto pelo livro, por um DVD de multimídia e por uma guia para o professor.

O livro Nuovo Espresso 2 (BALİ; RIZZO, 2014) (NE2) é o segundo da coleção NE da editora Alma Edizioni. A coleção Espresso existia já há mais de uma década e, conforme as autoras, foi reformulada, trazendo não edições atualizadas do mesmo método, mas um verdadeiro novo curso, com novas atividades de leitura, de audição, novos exercícios, um enriquecimento da seções intituladas Caffè culturale, seções de exercícios atualizadas e ampliadas e uma página de abertura para cada lição.

O volume 2 dessa nova coleção traz, ainda, um vídeo-curso acompanhado por uma vídeogramática inseridos no DVD de multimídia. A nova coleção traz a novidade do acesso gratuito ao site da editora, do qual o usuário pode descarregar e utilizar diversos materiais extras.

Essa nova coleção é formada por cinco volumes, que vão do nível A1 ao nível C1 do Quadro Comune Europeu di Riferimento (QCER). Os dois últimos volumes, NE4 e NE5 foram lançados no ano em curso. O livro didático de NE2 contém dez unidades didáticas (p.05-158), uma seção composta por exercícios e testes (p.159-232), um apêndice gramatical (p.233-251) e um apêndice destinado às respostas dos exercícios (p.252-263). Além disso, o material traz quatro seções extras intituladas Facciamo il punto, composta, cada uma, por jogos, síntese da aprendizagem (bilancio) e projeto. A primeira dessas quatro seções aparece ao término da unidade 2; a segunda, ao término da unidade 5; a terceira, ao término da unidade 7; a quarta, ao término da unidade 10 .

Em consonância às ultimas tendências apontadas por especialistas na era do "pós-método" como Borneto (1998), Kumaravadivelu (2006) e Santoro (2011), a concepção do NE2 tem 
como premissa a abordagem comunicativa e incorpora algumas das recentes estratégias para reforçar o protagonismo e engajamento do aluno no processo de ensino aprendizagem através da inserção periódica de projetos ao longo do curso, por exemplo.

\subsection{A sequência didática do imperfetto no $\mathrm{NE2}$}

No NE2, o imperfetto surge pela primeira vez na unidade didática 2. De acordo com o índice, são abordados, nessa unidade, os seguintes elementos gramaticais:
a. formas e usos do imperfetto;
b. o uso do passato prossimo e do imperfetto;
c. expressões de tempo com o imperfetto e com o passato prossimo.

A fim de se atingir as seguintes habilidades comunicativas
a. falar das próprias recordações;
b. descrever hábitos do passado;
c. descrever situações;
d. argumentar a favor e contra.

Após um hiato de duas unidades, o imperfetto volta a ser tema gramatical na unidade 5, na qual são apresentados:
a. o uso do verbo volere no imperfetto;
b. os verbos sapere e conoscere no passato prossimo e no imperfetto;
c. o uso do passato prossimo e do imperfetto;

A fim de se atingir as seguintes habilidades comunicativas:
a. pedir algo de forma cortês;
b. mostrar-se disposto a escutar alguém;
c. mostrar-se contente por uma proposta;
d. exprimir surpresa e descontentamento;
e. informar-se sobre algo; 
f. perguntar a duração de uma viagem;

g. perguntar o preço.

A partir dos protótipos da sequência didática (modelli operativi) previstos pelos linguistas que pesquisam e ensinam a língua italiana como língua segunda no âmbito da glottodidattica, descreveremos a seguir as etapas e as estratégias previstas em cada uma das fases de desenvolvimento e progressão dos argumentos em relação ao imperfetto dentro das unidades 2 e 5 .

Bem como aponta Pona (2015, p.1), embora sejam convergentes, as nomenclaturas das fases da sequência didática propostas por Balboni (2002, 2008, 2012 - unità di apprendimento/ unità di acquisizione), Vedovelli (2002, 2010 - Unità didattica centrata sul testo) e Diadori (2009) e Diadori; Palermo; Troncarelli (2009, - unità di lavoro) possuem, em sua definição teórica primordial, algumas nuances teóricas fundamentais que as diferenciam. Enquanto as premissas do modelo de Balboni (que fundamentam também os modelos endossados por Freddi, 1994 e Porcelli, 1994) são embasadas nos preceitos da psicologia da Gestalt e às noções de bimodalidade e direcionalidade propostas anteriormente por Marcel Danesi (1988), o paradigma proposto por Diadori e Vedovelli é desenvolvido a partir dos conceitos basilares de ensino-aprendizagem de Língua Estrangeira prescrito pelo Quadro Europeu Comum de Referência para as Línguas (QECR, 2001). 
Tab. 1: Equivalência entre os modelos de sequência didática propostos por Balboni $(2002,2012)$, Vedovelli $(2002,2010)$ e Diadori e

Diadori/Palermo/Troncarelli (adaptado de PONA, 2015).

\begin{tabular}{|c|c|c|c|}
\hline $\begin{array}{l}\text { Nomenclatura } \\
\text { das fases/ } \\
\text { sequências } \\
\text { didática e seus } \\
\text { respectivos } \\
\text { Autores }\end{array}$ & $\begin{array}{c}\text { Unità di } \\
\text { apprendimento (uda) } \\
\text { (Balboni 2002) } \\
\text { Unità di } \\
\text { acquisizione/ } \\
\text { (Balboni 2012) }\end{array}$ & $\begin{array}{l}\text { Unità didattica centrata sul testo } \\
\text { (Vedovelli 2002, 2010) }\end{array}$ & $\begin{array}{c}\text { Unità di lavoro } \\
\text { (Diadori, 2009) } \\
\text { e (Diadori/ } \\
\text { Palermo/ } \\
\text { Troncarelli } \\
\text { 2009) }\end{array}$ \\
\hline \multirow{6}{*}{ Fase } & Motivazione & Contestualizazzione & Introduzione \\
\hline & Globalità & Verifica della compreensione & \multirow{4}{*}{ Svolgimento } \\
\hline & Analisi & Attività di comunicazione sul testo & \\
\hline & Sintesi & Attività di comunicazione dal testo & \\
\hline & Riflessione & $\begin{array}{l}\text { Atividade metalinguística e } \\
\text { metacomunicativa/ } \\
\text { Attività esercitativa e di rinforzo }\end{array}$ & \\
\hline & Controllo & $\begin{array}{l}\text { Output comunicativo/output } \\
\text { comunicativo } \\
\text { Verifica in uscita }\end{array}$ & Conclusione \\
\hline
\end{tabular}

Para simplificar a análise que procederemos a seguir, utilizaremos a nomenclatura cunhada por Balboni $(2002,2010)$, por entendermos que os termos propostos pelo linguista (motivazione, globalità. analisi, sintesi, riflessione, controllo) contemplam de maneira satisfatória as reflexões dos outros especialistas supracitados.

\subsubsection{Unidade 2-NE2}

Veremos então como o imperfetto foi trabalhado nesta unidade, bem como quais orientações foram enfatizadas no Manual do Professor do Nuovo Espresso 2 (doravante MPNE2) para um melhor aproveitamento dos recursos do material didático e para o desenvolvimento e progressão dos assuntos abordados. O MPNE2 apresenta a unidade 2 (p.18) com a mesma apresentação gráfica presente no índice do próprio NE2: 
Fig. 1: Introdução das instruções concernentes à Unidade 2 no MPNE2 (p.19)

\begin{tabular}{|c|c|c|c|}
\hline & & Contenuti comunicativi & Grammatica e Lessico \\
\hline 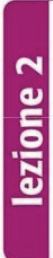 & $\begin{array}{l}\text { Quando ero } \\
\text { piccola... } \\
\text { - gli animali } \\
\text { - linfanzia } \\
\text { - le vacanze da bambini }\end{array}$ & $\begin{array}{l}\text { - parlare dei propri ricordi } \\
\text { - descrivere abitudini del passato } \\
\text { - descrivere situazioni } \\
\text { - argomentare a favore e contro qualcosa }\end{array}$ & $\begin{array}{l}\text { - forme e uso dell'imperfetto } \\
\text { - l'uso del passato prossimo e dell'imperfetto } \\
\text { (I) } \\
\text { - espressioni di tempo con l'imperfetto e con } \\
\text { il passato prossimo } \\
\text { - la particella } c i \\
\text { - il verbo fare } \\
\text { - gli alterati in -ino e -one } \\
\text { - alcuni falsi alterati }\end{array}$ \\
\hline
\end{tabular}

Apesar de o imperfetto (e seu respectivo contraste com o passato prossimo) ser apresentado já na página de abertura da unidade (p.21), em um pequeno quadro no qual constam algumas expressões como da piccolo avevo un cane; tu dove andavi in vacanza? Di solito andavamo al mare em contraste com outras expressões como una volta siamo andati al mare, segundo o MPNE2 o argumento gramatical em si será abordado apenas na seção 3 (Da piccola avevo un cane), a partir da página 23.

Para introduzir o argumento (fase da motivazione) as autoras apresentam um artigo retirado de La Repubblica, o qual versa sobre animais e exigência das crianças de protegê-los (p.22). $\mathrm{O}$ artigo apresenta o resultado de uma pesquisa realizada pelo Eurispes, que procurou saber se crianças queriam ter animais de estimação e que animais gostariam de ser. Além disso, o texto apresenta dados estatísticos sobre pessoas que têm ou já tiveram animais em casa.

Embora nesse texto não apareça nenhuma forma de imperfetto, percebemos que as autoras propõem uma abordagem indutiva para este que é o argumento gramatical principal da unidade, pois, ao unir os temas animais e crianças, propõem ativar no aprendiz as suas próprias recordações da sua infância. Logo após, seguindo o estilo que lhe é próprio, o livro apresenta uma atividade de léxico (p.23), que deve ser realizada com elementos dados pelo texto. A atividade é de ligação e o aprendiz deve relacionar a imagem do animal dado ao nome recolhido no texto. Em seguida, há uma atividade (2, p.23) de produção escrita e oral: uma entrevista por meio da qual se deve entrevistar um colega da turma, colhendo algumas informações sobre a sua relação com animais.

Após esse momento (fase da globalità), o livro apresenta um diálogo (3, p.23-24), sobre o qual o aprendiz deve verificar a sua compreensão auditiva, respondendo se são verdadeiras ou falsas as afirmações dadas. Em um segundo momento dessa atividade, é apresentada a transcrição do diálogo, na qual aparecem nove formas verbais de imperfetto inseridas em frases: da piccola avevo un cane, era un cane intelligentissimo, la mattina mi svegliava, mi accompagnava a scuola, quando tornavo a casa mi aspettava, riusciva a riconoscere il motore dell'autobus della scuola, noi avevamo tantissimi animali, voi vivevate in campagna, 
il tuo cane era contento con te. Ainda no exercício 3, há a indicação de buscar no texto "una nuova forma verbale al passato, l'imperfetto", e de inserir essas formas ao lado do infinitivo dado (fase da analisi). Feito isso, o aprendiz deve, a partir das formas encontradas, completar um tabela na qual constam quatro verbos conjugados no imperfetto: aspettare, vivere, riuscire e essere. A atividade apresenta, assim, o paradigma do imperfetto das três conjugações e do verbo cópula e irregular mais importante do italiano.

Segundo as instruções do MPNE2 para a apresentação do imperfetto na unidade (página 20), após uma rápida explicação sobre o uso do imperfetto e a constatação das regras de sua formação por parte dos alunos, seria recomendável a ênfase no seu uso e não na forma:

Recomendamos que o professor evite fornecer um excesso de noções gramaticais - uma vez que o imperfeito é um dos mais difíceis de digerir - e que prossiga lentamente, limitando-se nesta fase a destacar o uso desse tempo verbal. Sugerimos ainda que pergunte aos alunos quando, segundo o entendimento deles, é usado o imperfeito, estimulando-os com questões específicas. No final, é esperado que os professores sintetizem esta parte da regra: - usado para descrever o hábito do passado [...]; usado para descrever condições e estados psicológicos emocionais [...] (tradução nossa). ${ }^{8}$

De modo implícito, o livro apresenta, primeiramente o uso ao apresentar um diálogo em seu contexto de uso prototípico - isto é, os falantes que conversam sobre eventos do passado - e em seguida a forma. Nesse momento, ainda não foram apresentadas as funções e nem características do imperfetto. De fato, o material vai alternando atividades em que ora o aprendiz deve conjugar no imperfetto verbos dados no infinito, ora deve responder a perguntas que questionam sobre coisas do passado. Entres essas perguntas, destaca-se aquela em que o aprendiz deve descrever como era o animal de estimação que tinha quando criança (5. p.25). Percebemos aqui dois fatos importantes: fixar com o aluno a forma do verbo essere no imperfetto e o uso desse tempo verbal para descrever coisas/seres e situações e estados emocionais situados em um passado (correspondente à fase de sintesi)

8 No original: "Vi consigliamo di evitare difornire un eccesso di nozioni grammaticali-l'imperfetto è tra gli argomenti più ostici da 'digerire' - e di procedere lentamente, limitandovi in questa fase a evidenziare l'uso di questo tempo verbale. Chiedete agli studenti quando, secondo loro, viene adoperato, eventualmente stimolandoli con domande mirate. Alla fine sistematizzate questa parte della regola:-per descrivere un'azione abituale al passato [...] ;-per descrivere condizioni e stati psicologici ed emotivi [...]" 
No item 8 (p.26), as autoras retomam a abordagem do uso do imperfetto sob o tema dove andavi in vacanza? A atividade é de compreensão oral: a partir de um diálogo, o aprendiz deve responder quais das afirmações dadas estão corretas. O texto traz várias formas verbais no imperfetto, algumas acompanhadas de advérbios de frequência. O item seguinte, 9 , propõe uma atividade na qual o aprendiz deve retirar do texto do item 8 as formas usadas para expressar uma ação habitual no passado e aquelas (formas) usadas para expressar uma ação que aconteceu apenas uma vez no passado, já apontando para o contraste de uso entre o imperfetto e passato prossimo, que nortearão ainda os exercícios subsequentes. Aqui, já na fase de riflessione, é o momento em que o aprendiz deve refletir sobre as formas de palavras circunstancias - advérbios, frequentativos e pontuais - usados para expressar a habitualidade de ações e a unicidade delas. Esse exercício, além de alertar para as diferenças entre as formas do imperfetto e do passato prossimo, apresenta ao aluno outra característica do imperfetto: expressar a habitualidade de situações no passado. Os itens de 10 a 13 são exercícios que propõem ao aluno a prática do que foi apresentado. $\mathrm{O}$ item 10 é de completar com expressões dadas; o item 11 é de produção oral: falar sobre onde habitualmente se passavam as férias e se já tiveram alguma vez férias diferentes das habituais; o item 12 (primeiro texto literário apresentando no NE2) é de compreensão textual e de completar com algumas expressões previamente retiradas do texto, enquanto o item 13 seria reservado à prática de produção escrita e oral dos verbos no imperfetto a partir dos elementos fornecidos na unidade anterior. Por fim, as derradeiras páginas da unidade 2 (30 a 36) são destinadas à apresentação de novos elementos lexicais (no caso sobre nomes alterados) e são seguidos pelas atividades da síntese final das informações na etapa já na etapa do controllo, apresentadas na unidade através das atividades conjugadas com o videocorso, o jogo de revisão "Facciamo il punto" (p.34), uma atividade de autoavaliação e, finalmente, as instruções para um Projeto, uma atividade em grupo extraclasse para reiterar os conteúdos aprendidos e mobilizar o protagonismo dos alunos na produção de conhecimentos.

\subsubsection{Unidade 5}

Eis a apresentação dos conteúdos relacionados ao imperfetto da Unidade 5 do MPNE2 (página 44). 
Fig. 2: Introdução das instruções concernentes à Unidade 2 no MPNE2 (p.44)

\begin{tabular}{|l|l|l|}
\multicolumn{2}{c}{ Contenuti comunicativi } & \multicolumn{1}{c|}{ Grammatica e Lessico } \\
\hline Buon viaggio! & - chiedere qualcosa in modo gentile & - l'uso di volere all'imperfetto \\
- Ie vacanze & - mostrarsi disposti ad ascoltare qualcuno & - i verbi sapere e conoscere al passato prossimo \\
- illuoghi di villeggiatura & - mostrarsi contenti di una proposta & - l'uso del passato prossimo e dell'imperfetto \\
- raconti di viaggio & - esprimere sorpresa e dispiacere & (II) \\
& - informarsi su qualcosa & - il verbo volerci \\
& - chiedere la durata di un viaggio & \\
\hline
\end{tabular}

Nesse segundo momento de reiteração e progressão do imperfetto no NE2 (e seu respectivo contraste com o passato prossimo, bem como particularidades dos verbos modais nos tempos supraelencados), as autoras escolheram o tema viagem como o argumento condutor dessa sequência didática. Assim, na fase de motivazione, as autoras fornecem uma lista de palavras e expressões úteis na página de abertura da unidade (p.67) para, em seguida, ativar e relacionar os conhecimentos prévios dos alunos através de um questionário no qual os aprendizes são instados a descrever seus hábitos quando estão de férias (p.68 e 69). Ainda na página 69, há uma atividade de compreensão oral, um diálogo no qual são introduzidas as principais estruturas gramaticais que serão esmiuçadas na referida unidade. A seguir, na página 70 , para progredir para o momento da globalità, as autoras apresentam a transcrição do diálogo e fazem perguntas pontuais sobre o léxico (expressões usadas para pedir alguma coisa de modo gentil, mostrar a disponibilidade para escutar alguém, exprimir surpresa, mostrar-se satisfeito com a proposta feita por uma outra pessoa) e ativam já a fase de analisi ao solicitarem aos aprendizes a diferenciação dos significados dos verbos sapere e conoscere e suas particularidades quando empregados no passato prossimo ou imperfetto. Assim como previsto na Unidade 2, a orientação para os professores é de prima di passare alla spiegazione invitate gli studenti a riflettere autonomamente e poi a coppie sull'uso dei due tempi verbali (MPNE2, p.44), com o objetivo de sublinhar o uso/contraste e não a forma dos respectivos tempos verbais. Nas páginas 71 e 72 (itens: 3 - Volevo...; 4 - Ho Saputo che ...; 5 - Vilaggio turistico pro e contro; 6 - La Toscana in moto) é desenvolvida a fase da sintesi na qual os aprendizes são convidados a produzirem sobretudo textos orais a partir de uma ligeira interpretação e reelaboração das informações apresentadas na fase anterior, com o objetivo de fixar os conteúdos. Nas instruções do MPNE2 (p.44 e 45) para essas atividades foram enfatizados, sobretudo, a fixação do léxico e das estruturas gramaticais relacionadas ao passato prossimo/imperfetto, ainda que de forma implícita.

No item 7, Riflettiamo (página 73) é o momento pontual no qual as autoras estimulam a fase de riflessione dos aprendizes por intermédio da análise das estruturas presentes na atividade 
anterior (item 6 - La Toscana in moto), que narra os acontecimentos de uma viagem de dois personagens no passado e apresenta ações no passado concluídas, sentimentos ou intenções do passado e a descrição de pessoas, coisas e situações do passado. São ainda orientações das autoras no MPNE2 (p.46):

Lembrem-se de que os alunos estão refletindo por conta própria e, portanto, não os desencorajem se fizerem hipóteses erradas. Uma leitura adicional deve esclarecer melhor o uso do imperfeito para descrever sentimentos, condições e estados de espírito do passado em contraste com uso do passado prossimo para expressar ações pontuais e concluídas. É importante que o professor se certifique de verificar se os alunos colocados em duplas estão interagindo para alcançar o objetivo proposto e que conclua com uma retomada do tema em conjunto com toda a classe. (tradução nossa). ${ }^{9}$

As atividades 8 - Diario di viaggio, 9 - Ti racconto del mio viaggio, 10 - Ma davvero?, 11 - Che sfortuna!, bem como as presentes na seção E inoltre... (1 - Vorrei qualche infomazione e 2 - In un'agenzia di viaggi) propostas nas páginas subsequentes (páginas 73 a 77) são privilegiadas às etapas inerentes ao controllo, integradas ainda pela seção Grammatica, além das atividades do Videocorso, Facciamo il punto e Progetto, analogamente ao que já tinha sido apresentado na Unidade 2.

Para concluir, analisemos rapidamente o quadro síntese de atividades propostas pelas unidades 2 e 5 de acordo com os momentos didáticos apresentados pelas autoras:

9 No original: "Ricordate che gli studenti stanno riflettendo da soli, pertanto non scoraggiateli di fronte a ipotesi sbagliate. Un'ulteriore lettura dovrebbe chiarire meglio l'uso dell'imperfetto per descrivere sentimenti, condizioni e stati d'animo al passato e del passato prossimo per esprimere azioni puntuali, concluse. Fate controllare come sempre a coppie e concludete con una verifica in plenum." 
Tab. 2: Quadro síntese de atividades das Unidades 2 e 5 de acordo com as fases didáticas (adaptado de PONA, 2015)

\begin{tabular}{|c|c|c|c|}
\hline $\begin{array}{c}\text { Fases } \\
\text { didáticas }\end{array}$ & Técnicas da glottodidatica & $\begin{array}{c}\text { Unidade 2- } \\
\text { quando ero } \\
\text { piccola... }\end{array}$ & $\begin{array}{c}\text { Unidade } \\
\text { 5- buon } \\
\text { viaggio! }\end{array}$ \\
\hline \multirow{16}{*}{ Motivazione } & Brainstorming & & $\mathrm{X}$ \\
\hline & Mapa mental & & \\
\hline & Antecipação & $\mathrm{X}$ & $\mathrm{X}$ \\
\hline & Emprego de realia, imagens, vídeos, etc. & $\mathrm{X}$ & $\mathrm{X}$ \\
\hline & Quem? O quê? Onde? Quando?... & & $\mathrm{X}$ \\
\hline & Verdadeiro ou falso & $\mathrm{X}$ & \\
\hline & Perguntas de múltipla escolha & & $\mathrm{X}$ \\
\hline & Perguntas abertas & & $\mathrm{X}$ \\
\hline & Tabela & $\mathrm{X}$ & \\
\hline & Encontrar o correspondente (matching) & $\mathrm{X}$ & \\
\hline & Reordenar & & \\
\hline & Completar espaços vazios (cloze) & & \\
\hline & Áudio-repetição & & \\
\hline & Áudio- leitura silenciosa & $\mathrm{X}$ & \\
\hline & Ditado, resumo, elaborar anotações, paráfrases & & $\mathrm{X}$ \\
\hline & Completar espaços vazios (específico) & $\mathrm{X}$ & $\mathrm{X}$ \\
\hline \multirow{5}{*}{ Analisi } & Inclusão & $\mathrm{X}$ & $\mathrm{X}$ \\
\hline & Exclusão & $\mathrm{X}$ & $\mathrm{X}$ \\
\hline & Numeração/seriação & & \\
\hline & Explicitação & & \\
\hline & Role taking, role play & $\mathrm{X}$ & $\mathrm{X}$ \\
\hline \multirow{6}{*}{ Sintesi } & Diálogo e corrente & & \\
\hline & Diálogo aberto & $\mathrm{X}$ & $\mathrm{X}$ \\
\hline & Diálogo em duplas & $\mathrm{X}$ & \\
\hline & Conversação de grupo & & \\
\hline & Composição textual & $\mathrm{X}$ & $\mathrm{X}$ \\
\hline & Monólogo & & \\
\hline
\end{tabular}




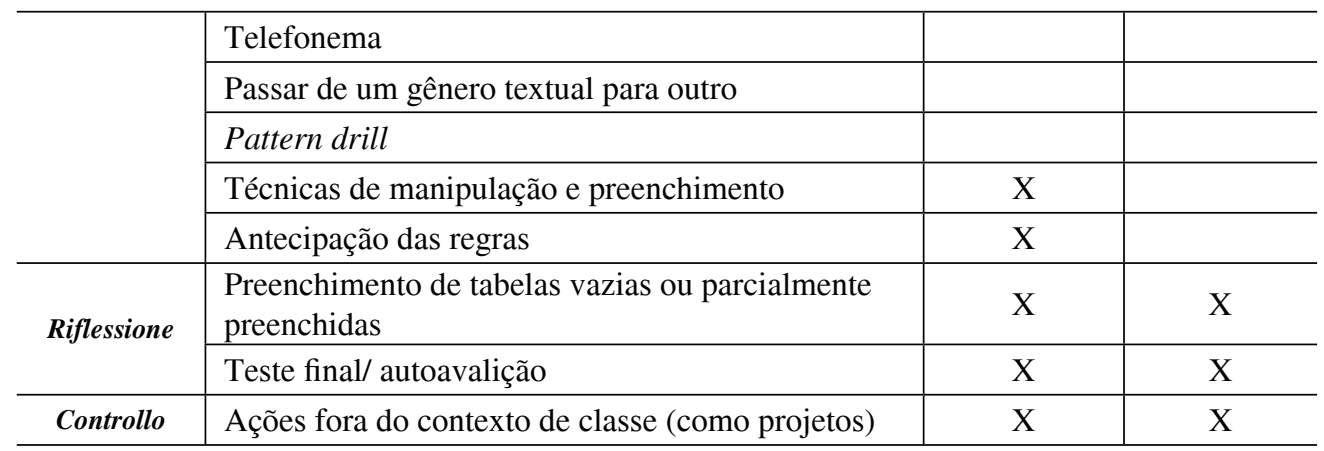

\section{Análise do Imperfetto}

No caderno de exercícios, selecionamos as unidades correspondentes àquelas do livro do estudante no qual o conteúdo é tema central. Neste, procedemos da seguinte maneira:

1. Primeira etapa: um levantamento do tipo de exercício em que as formas do imperfetto estavam presentes. Neste levantamento, encontramos atividades do tipo:

Completar (tabela, texto - com formas verbais ou com outros elementos do texto - frases - apenas com formas ou identificando funções);

Ligar frases;

Escolher a expressão adequada;

Identificar funções.

2. Segunda etapa: quantificação das formas verbais presentes (ou ausentes, mas a serem preenchidas) em cada atividade. A quantificação destas foi realizada levando-se em consideração os três tipos de imperfetto italiano do modo realis (SERIANNI, 1988): iterativo, descritivo e narrativo.

A caracterização e a quantificação dos dados estão resumidas nas tabelas a seguir, as quais foram elaboradas conforme as unidades do material didático. A informação entre colchetes corresponde à ordem em que o exercício é apresentado no caderno de exercícios; os números nas colunas ITERATIVO, DESCRITIVO e NARRATIVO correspondem ao total de cada ocorrência no exercício apontado. Por exemplo, onde se lê: completar tabela (apenas formas) [2], entenda-se que: no exercício 2, o aprendiz deve completar uma tabela usando as formas 
do imperfetto; das formas usadas para o preenchimento, 9 possuem a função iterativa, 3 possuem a função descritiva e nenhuma (0) possui a função narrativa.

Tab. 3: Caracterização e quantificação das formas/funções do imperfetto nos exercícios da unidade 2

\begin{tabular}{|c|c|c|c|c|}
\hline \multirow{2}{*}{\multicolumn{2}{|c|}{ Iterativo }} & \multicolumn{3}{|c|}{ Tipo de imperfetto } \\
\hline & & \multirow{2}{*}{$\begin{array}{c}\text { Descritivo } \\
9\end{array}$} & \multirow{2}{*}{$\frac{\text { Narrativo }}{3}$} & \\
\hline \multirow{10}{*}{$\begin{array}{l}\text { Tipo } \\
\text { de } \\
\text { atividade }\end{array}$} & Completar tabela (apenas formas) [2] & & & 0 \\
\hline & Completar (com formas verbais) texto [3] & 7 & 3 & 0 \\
\hline & Completar (com outros elementos) texto [9] & 0 & 3 & 0 \\
\hline & Completar frases (apenas formas) [4] & 7 & 7 & 0 \\
\hline & Completar frases (identificando função) [12] & 3 & 6 & 0 \\
\hline & Formar frases [5] & 5 & 1 & 0 \\
\hline & $\begin{array}{l}\text { Escolher a expressão (locuções adverbiais/ } \\
\text { advérbios frequentativos ou pontuais) adequada } \\
{[6] \text { : }}\end{array}$ & 6 & 1 & 0 \\
\hline & $\begin{array}{l}\text { Escolher a expressão (locuções adverbiais/ } \\
\text { advérbios frequentativos ou pontuais) adequada } \\
\text { [7]: }\end{array}$ & 5 & 2 & 0 \\
\hline & Ligar frases [8] & 3 & 2 & 0 \\
\hline & $\begin{array}{l}\text { Identificar funções (descrição, habitualidade) } \\
{[10]}\end{array}$ & 8 & 4 & 0 \\
\hline & Total & 53 & 32 & 0 \\
\hline
\end{tabular}


Tab. 4: Caracterização e quantificação das formas/funções do imperfetto nos exercícios da unidade 5

\begin{tabular}{l|l|c|c|c}
\hline \multicolumn{2}{c|}{ Iterativo } & \multicolumn{2}{c}{ Tipo de imperfetto } \\
\cline { 3 - 5 } \multicolumn{2}{c|}{} & Descritivo & Narrativo & \\
\hline \multirow{4}{*}{$\begin{array}{l}\text { Tipo de } \\
\text { atividade }\end{array}$} & Completar (com formas verbais) texto [5] & & & \\
\cline { 2 - 5 } & Completar (com formas verbais) texto [7] & 0 & 6 & 0 \\
\cline { 2 - 5 } & Completar (com formas verbais) texto [8] & 2 & 6 & 0 \\
\hline \multirow{4}{*}{} & Completar (com formas verbais) texto [10] & 0 & 4 & 0 \\
\cline { 2 - 5 } & Completar (com formas verbais) texto [15] & 0 & 5 & 0 \\
\cline { 2 - 5 } & Completar (com formas verbais) frases [6] & 0 & 4 & 0 \\
\cline { 2 - 5 } & Ligar frases [4] & 0 & 2 & 0 \\
\cline { 2 - 5 } & Atribuir funções às formas (cortesia) [3] & 0 & 3 & 0 \\
\hline Total & \multicolumn{2}{|c|}{2} & 37 & 0 \\
\hline
\end{tabular}

Tab. 5: Caracterização e quantificação das formas/funções do imperfetto nos exercícios da seção TEST 2

\begin{tabular}{c|c|c|c|c}
\hline \multicolumn{2}{c|}{ Iterativo } & \multicolumn{3}{c}{ Tipo de imperfetto } \\
\cline { 3 - 5 } \multicolumn{2}{c|}{} & Descritivo & Narrativo & \\
\hline \multirow{2}{*}{$\begin{array}{c}\text { Tipo de } \\
\text { atividade }\end{array}$} & Completar (com formas verbais) texto [5] & 2 & 5 & 0 \\
\cline { 2 - 5 } & Completar (com formas verbais) texto [6] & 1 & 1 & 0 \\
\hline \multicolumn{2}{c}{ Total } & 3 & 6 & 0 \\
\hline
\end{tabular}

Tab. 6: Caracterização e quantificação total das formas/ funções do imperfetto nos exercícios

\begin{tabular}{c|c|c}
\hline \multicolumn{3}{c}{ Total } \\
\hline \multicolumn{3}{c}{ Tipo de imperfetto } \\
\hline Iterativo & Descritivo & Narrativo \\
\hline 56 & 75 & 0 \\
\hline
\end{tabular}


Quanto à relação forma/função, o levantamento das ocorrências das formas verbais relacionadas aos tipos de imperfetto na fase de controllo da unidade 2, conforme a tabela 3 , evidencia uma maior ocorrência da função iterativa $(62 \%)$ em detrimento de uma menor ocorrência da função descritiva $(37 \%)$ e nenhuma ocorrência da função narrativa. Conclui-se que as autoras, nessa etapa, enfatizam a expressão da repetição de ações passadas. De fato, no livro, o item 8 (p.26) traz um texto que contém algumas formas verbais no imperfetto acompanhadas de advérbios de frequência, seguido do item 9, que propõe uma atividade na qual o aprendiz deve retirar do texto do item 8 as formas usadas para expressar uma ação habitual no passado e aquelas (formas) usadas para expressar uma ação que aconteceu apenas uma vez no passado, apontando para o contraste de uso entre o imperfetto e passato prossimo, que nortearão ainda os exercícios subsequentes. Aqui, já na fase de riflessione, é o momento em que o aprendiz deve refletir sobre as formas de palavras circunstâncias advérbios, frequentativos e pontuais - usados para expressar a habitualidade de ações ou a unicidade delas. Esse exercício, além de alertar para as diferenças entre as formas do imperfetto e do passato prossimo, apresenta ao aluno outra característica do imperfetto: expressar a habitualidade de situações no passado, relacionando a essas funções as situações comunicativas/pragmáticas de narrar viagens de férias, falar de hábitos e costumes do passado.

Em relação à unidade 5, a tabela 4 evidencia exatamente o contrário: é dada maior ênfase à função descritiva do imperfetto (94\%) e pouca atenção à função iterativa $(5,12 \%)$. Novamente, a função narrativa não é abordada. Nessa etapa do percurso didático, as autoras apostam na função comunicativa/pragmática da expressão de sentimentos ou intenções do passado e a descrição de pessoas, coisas e situações do passado. Além disso, são apresentadas as diferenças dos significados dos verbos sapere e conoscere que, segundo as autoras "têm dois significado diferentes para o passato prossimo e o imperfetto (p.70), que seriam "receber novas informações, saber alguma coisa há um longo tempo, conhecer uma pessoa, conhecer uma pessoa ou algo há muito tempo". Esses dois verbos, quando usados no imperfetto, indicam uma indeterminação de tempo ("molto tempo"): "non sapevo che hai ancora dei nonni" "io conoscevo già il villaggio" (p.77), e, por conseguinte, descrevem uma situação, o que realça os valores descritivos dessa forma verbal.

A tabela 5 mostra que, na seção de testes, onde o aprendiz faz uma autoavaliação do quanto aprendido, a quantidade de formas com função descritiva corresponde ao dobro de formas com função iterativa: $66,6 \%$ e 33,3\%, respectivamente. Não há ocorrências da função narrativa.

Em relação ao percentual total da relação forma/função, a tabela 6 mostra que a função iterativa apresenta um percentual menor de ocorrências, 42,7\%, do que a função descritiva, $57,2 \%$, em um universo de 131 formas. 


\section{Considerações finais}

Neste trabalho, apresentamos os resultados de uma breve pesquisa que buscou trazer à luz as particularidades do imperfetto em sua abordagem no manual Nuovo Espresso 2.

Para tanto, apresentamos importantes considerações sobre a classe verbal e duas de suas categorias, o Tempo e o Aspecto (BERTINETTO, 1886; COROA 2005; COSTA, 1997; TOTH, 1999a, 1999b), relacionando-as às elucubrações sobre o passado imperfectivo da língua italiana sistematizadas por Farkas (1998) e Serianni (1988).

Paralelamente ao aspecto gramatical, procuramos acrescentar considerações sobre os procedimentos didáticos de apresentação do imperfetto no referido material, baseados, sobretudo, em Balboni (2002), a fim de verificar a abordagem dada às funções do imperfetto estabelecidas pelos linguistas em apreço e compreender a progressão dos argumentos ao longo das unidades.

Conforme exposto em seção anterior, são abordadas as funções iterativa e descritiva do passado imperfectivo do italiano, o imperfetto. Para tanto, o material parte da apresentação de textos motivadores e prototípicos da ocorrência dessas funções, a fim de que o aprendiz alcance as seguintes competências comunicativas: narrar fatos da infância, contar sobre viagens e hábitos do passado ou descrever situações passadas; e encerra com exercícios de verificação da aprendizagem que contemplam a capacidade do aprendiz de relacionar, completar tabela, textos, com formas verbais ou com outros elementos do texto, completar e/ou ligar frases, escolher a expressão adequada e identificar funções.

Ao longo das duas unidades em que o imperfetto é tema central, as autoras equilibram a relação forma/função, privilegiando, na unidade 2 , a função iterativa, fazendo uso de textos e exercícios em que o aprendiz discorra sobre fatos e atividades habituais do passado e reconheça a diferença entre a repetição e a pontualidade destes; para, na unidade 5, dar ênfase à função descritiva, utilizando textos, exercícios e propondo situações comunicativas em que o aprendiz seja capaz de descrever situações do passado.

Embora haja um equilíbrio na apresentação dessas duas funções, os dados colhidos atestam que as autoras não apresentam no material didático a função narrativa do imperfetto, desconsiderando-a totalmente. Desperta a nossa atenção o fato de, no MPNE2, as autoras destacarem, nas instruções sobre o exercício 12 da unidade 2 do livro do estudante (p.28), que nessa referida atividade aparece "o primeiro texto literário presente no Nuovo Espresso 2". No entanto, ao verificarmos a atividade proposta, constatamos que, embora tenha sido escrito por uma grande escritora da língua italiana, Dacia Maraini, e tenha sido apresentado como literário, o texto é um fragmento de uma entrevista presente em uma compilação de entrevistas publicadas anteriormente em uma revista de grande circulação, de acordo com a informação presente na abertura do livro em questão (MARAINI, 1993). 
Pensamos que as autoras poderiam ter aproveitado o espaço e apresentado um texto narrativo no qual constassem, de fato, formas do imperfetto com a função narrativa, conforme a definição estabelecida por Serianni (1988), uma vez que o texto narrativo é o local mais propício à ocorrência desse par forma/função, contemplando, assim, as três funções do imperfetto no âmbito do realis. Em vez disso, as autoras se valem desse texto, presumidamente literário, para reforçar a função iterativa do imperfetto.

Longe do definitivo e do acabado, este trabalho, que privilegia as particularidades de apenas uma forma verbal abordada em apenas um material didático de italiano como língua estrangeira, em hipótese alguma teve a pretensão de esgotar tema tão rico. Desejando ter colaborado para a construção de conhecimentos e reflexões sobre o ensino de italiano LE, esperamos que este trabalho possa representar o descortinar de pesquisas futuras em que sejam analisados de forma profunda, acurada e detalhada os materiais didáticos de italiano LE utilizados no ensino da língua ao público brasileiro, a fim de que sejam investigados os procedimentos e a complexidade da abordagem de temas gramaticais, comunicativos e culturais imprescindíveis à formação de um usuário competente, isto é, de um usuário que saiba não apenas usar a língua aprendida de maneira adequada aos diversos contextos sócio-comunicativos, como refletir sobre os usos e suas implicações pragmáticas.

\section{Referências}

BALBONI, P. Le sfide di Babele. Insegnare le lingue nelle società complesse. Torino, UTET, 2002 (2010 - nova edição).

BALÌ, M.; RIZZO, G. Nuovo Espresso 2. Libro dello studente e esercizi. Firenze, Alma Edizioni, 2014.

. Nuovo Espresso 2. Guida per l'insegnante. Firenze, Alma Edizioni, 2014.

BERTINETTO, P. M. Le perifrasi abituali in italiano ed in inglese. Studi Orientali e Linguistici 6 (1995/96). Bologna, Editore CLUEB, 1996, p.117-133. Disponível em: http://linguistica.sns.it/QLL/ QLL94/PMB.PerifrasiAbituali.pdf. Acesso: 10 de agosto de 2017.

Tempo, aspetto e azione nel verbo italiano: Il sistema dell'indicativo. Firenze, Accademia della Crusca, 1986.

BORNETO, C. S. C'era una volta il metodo. Tendenze attuali della didattica delle lingue straniere. Roma, Carocci Editore, 1998.

COAN, M; BACK, A. REIS, M. FREITAG, R. As categorias verbais tempo, aspecto, modalidade e referência: pressupostos teóricos para uma análise semântico-discursiva. Estudos Lingüísticos, Campinas, São Paulo, v. 35, p.1463-1472, 2006.

CORÔA, M. L. M. S. O tempo nos verbos em português: uma introdução à sua interpretação semântica. São Paulo, Parábola, 2005. 
COSTA, S. B. B. O aspecto em português. 2.ed. São Paulo, Contexto, 1997.

DIADORI, P. Quali modelli operativi per l'italiano L2? L'unità di lavoro. In: Diadori, P. (a cura di). La DITALS risponde 6. Perugia, Guerra Edizioni, 2009.

DIADORI, P; PALERMO, M., TRONCARELLI, D. Manuale di didattica dell'italiano. Perugia, Guerra, 2009.

FARKAS, M. Le funzioni dell'imperfetto "modale" italiano in ungherese. Analisi a confront. Nuova Corvina: Rivista di Italianistica dell'Istituto di Cultura per l'Ungheria, Budapeste, n. 4, p.69-74, 1998.

FREDDI, G. Glottodidattica: fondamenti, metodi, tecniche. Torino, UTET, 1994.

FREITAG, R. M. K. Aspecto inerente e passado imperfectivo no português: atuação dos princípios da persistência e da marcação. Alfa, São Paulo, 55 (2): 477-500, 2011.

JAKOBSON, R. Linguística e Comunicação. São Paulo, Cultrix/Edusp, 1969, trad. de J. Paulo Paes e I. Blikstein.

KUMARAVADIVELU, B. Understanding language teaching: from method to postmethod. New York, Routledge, 2006.

PEZZATI, E. G. O funcionalismo em linguística. In: Mussalim, F.; Bentes, A. C. (orgs.). Introdução à linguística: fundamentos epistemológicos. V.3, 5. ed. São Paulo, Cortez, 2011. p.165-217.

PONA, A. Modelli operativi nella didattica dell'italiano come Lingua Seconda. In: Materiali diddatici per il ciclo di incontri "Didattica dell'Italiano come Lingua Seconda: il ruolo della Biblioteca Lazzerini di Prato sul territorio. Prato: Biblioteca Comunale Lazzerini, 2015. Disponível em: <http://allegati. ponet.prato.it/dl/20150122133635783/Modelli_operativi_nella_didattica_dell_italiano_L2_Alan_Pona. pdf $>$. Acesso em 26 de agosto de 2017.

PORCELLI, G. Principi di glottodidattica. Brescia, La Scuola, 1994.

REICHENBACH, H. Elements of symbolic logic. Nova York, The MacMillan Company, 1948 [1947].

SANTORO, E. Tradução e ensino de línguas estrangeiras: confluências. Cadernos de Tradução, Florianópolis, v. 1, n. 27, p. 147-160, nov. 2011. ISSN 2175-7968. doi: http://dx.doi.org/10.5007/21757968.2011v1n27p147. Disponível em: <https://periodicos.ufsc.br/index.php/traducao/article/view/21757968.2011v1n27p147>. Acesso em 07 de setembro de 2017.

SALVI, G; VANELLI, L. Grammatica essenziale di riferimento della lingua italiana. Firenze, Le Monnier, 1992.

SENSINI, Marcello. La Grammatica della Lingua Italiana. Milano, Mondadori, 1990.

SERIANNI, Luca. Grammatica Italiana. Torino, UTET, 1988.

TÓTH, L. Contributi ai valori dell'imperfetto italiano. Nuova Corvina: Rivista di Italianistica dell'Istituto di Cultura per l'Ungheria, Budapeste, n. 5, p. 247 - 255, 1999a.

TÓTH, L. Sulla globalità dell' azione (in relazione all'imperfetto "narrativo" e all' aspetto “inclusivo"). In: Nuova Corvina: Rivista di Italianistica dell'Istituto di Cultura per l'Ungheria, Budapeste, n. 6, p. 135 $-141,1999 b$ 
VARGAS, M. V. Verbo e práticas discursivas. São Paulo, Contexto, 2011.

VEDOVELLI, Massimo. L'italiano degli stranieri: storia, attualità e prospettive. Roma, Carocci, 2002.

Recebido em 20/09/2017

Aprovado em 22/11/2017 